\title{
AVALIAÇÃO DE QUALIDADE EM INTERPRETAÇÕES DE CONFERÊNCIA E COMUNITÁRIA
}

\author{
Franz Pöchhacker ${ }^{1}$ \\ -University of Vienna. Viena, Áustria
}

Tradução de ${ }^{1}$ :

Diego Mauricio Barbosa² Paulo Roberto Mathias Manes 2

${ }^{2}$ Universidade Federal de Goiás. Goiânia, Goiás, Brasil

Patrícia Rodrigues Costa $^{3}$ ${ }^{3}$ Universidade de Brasília. Brasília, Distrito Federal, Brasil

Revisão da tradução de:

Markus J. Weininger ${ }^{4}$

${ }^{4}$ Universidade Federal de Santa Catarina, Florianópolis, Santa Catarina, Brasil

\section{Nota à Tradução}

Nos últimos anos, os Estudos da Interpretação têm ganhado espaço na Academia, com destaque para os Estudos sobre a Qua-

\footnotetext{
${ }^{1}$ Artigo publicado na Meta. A tradução para o português do Brasil deste artigo e sua publicação foram autorizadas pelo autor e por Sandra Soucy, diretora de produção e administração de editora Les Presses de l'Université de Montréal, detentora dos direitos autorais das publicações da revista Meta. Referência do artigo publicado na revista Meta: Pöchhacker, Franz. Quality Assessment in Conference and Community Interpreting. Meta, v. 46, n. 2, 2001, pp. $410-425$ https://doi.org/10.7202/003847ar.
} 
lidade na Interpretação, sobretudo aqueles relacionados à interpretação simultânea. O artigo, aqui traduzido, Quality Assessment in Conference and Community Interpreting (Pöchhacker 2001), é um exemplo da necessidade de se pensar e discutir essa temática imprescindível aos estudiosos e profissionais da área. Como evidenciado por Pöchhacker, é preciso buscar respostas às lacunas ainda presentes no que se refere à atividade interpretativa como um todo e, em especial, a uma avaliação prática de como estamos buscando uma "qualidade em todas as áreas".

Nestas últimas duas décadas, fomos apresentados a publicações internacionais oriundas de pesquisas e congressos valiosos, tais como os livros The Critical Link 5: Quality in Interpreting - a shared responsibity, publicado, em 2009, como fruto de congresso internacional homônimo organizado por Ozolins e Hale, e Testing and Assessment of Interpreting: Recent Developments in China (2021) organizado por Jing Chen e Chao Han datado de 2021.

No Brasil, pesquisadores da grande área dos Estudos da Interpretação (línguas de sinais e línguas orais) têm realizado ações com temáticas que entrelaçam os Estudos sobre a Qualidade na Interpretação Simultânea, a saber: (i) $1^{\circ}$ Simpósio Brasileiro de Interpretação (SIMBI) realizado em 2013; (ii) os números temáticos publicados na Tradução em Revista, organizados pelos professores, pesquisadores e intérpretes Raffaella de Filippis Quental, Christiano Sanches do Valle Silva e Denise de Vasconcelos Araujo, em 2017 e 2018; (iii) o Congresso sobre Estudos da Interpretação (CONEI) proposto, em 2019, pelo professor doutor Diego Mauricio Barbosa (Universidade Federal de Goiás) como um evento multi-institucional em parceria com os professores doutores Guilherme Lourenço (Universidade Federal de Minas Gerais), Silvana Aguiar dos Santos (Universidade Federal de Santa Catarina), Patrícia Tuxi (Universidade de Brasília) e os professores mestres Raffaella de Filippis Quental e Christiano Sanches do Valle (ambos da Pontifícia Universidade Católica do Rio de Janeiro).

Nesses movimentos, pode-se perceber iniciativas para consolidar e fortalecer a área dos Estudos da Interpretação. Ademais, 
pode-se constatar e evidenciar os Estudos sobre a Qualidade na Interpretação Simultânea como um objeto multidisciplinar que contempla inúmeras discussões, como: formação para/do intérprete; estudos sobre o processo de interpretação; estudos sobre o produto do ato interpretativo etc. Vale ressaltar, no entanto, que consideráveis discussões ainda se fazem cruciais para a área, principalmente no que tange as diferentes perspectivas e expectativas sobre a qualidade da interpretação (produtor do texto-fonte, intérprete/equipe de intérpretes, receptor da interpretação, o cliente que contrata) e a triangulação desses dados.

A tradução, aqui apresentada, do artigo de Franz Pöchhacker visa, portanto, trazer ao público brasileiro questões ainda atuais e primordiais para os Estudos da Interpretação, mesmo após 20 anos de sua publicação na revista acadêmica canadense Meta, e assim contribuir para a ampliação dessa temática.

Diego Mauricio Barbosa Universidade Federal de Goiás

\section{Introdução}

Na sessão de encerramento da Primeira Conferência sobre Interpretação Comunitária BABELEA, realizada, em Viena, no início de novembro de 1999, Rocco Tanzilli, chefe do Serviço Conjunto de Interpretação de Conferências da Comissão Europeia, abordou as preocupações dos profissionais da interpretação comunitária e dos pesquisadores ao exigir elevados padrões de qualidade para qualquer tipo de atividade de interpretação, em suma: "qualidade em todas as áreas". Posto que a garantia de qualidade implica alguma forma de avaliação de qualidade, e esta por sua vez, requer uma base conceitual e metodológica sólida, o presente artigo visa realizar um levantamento do estado da arte dos Estudos da Interpretação no que diz respeito à questão da qualidade e sua avaliação.

Cad. Trad., Florianópolis, v. 41, $\mathbf{n}^{0}$ esp. 2, p. 354-384, ago/dez, 2021.356 
Com vistas a preparar o terreno para esta discussão, primeiro discutirei a noção de qualidade, bem como os critérios e os padrões pelos quais a qualidade deve ser avaliada. A parte principal deste trabalho será, então, dedicada a uma revisão das abordagens de pesquisa e descobertas concernentes aos vários aspectos de qualidade e tipos de interpretação. Em vez de proporcionar uma revisão abrangente de toda e qualquer pesquisa relacionada à qualidade, o escopo deste artigo se limita a um panorama de várias abordagens metodológicas, com referência a alguns estudos exemplares. Com base nisso, vou tentar mostrar se, e em que medida, pesquisas sobre interpretação relacionadas à qualidade podem se beneficiar de vínculos entre diferentes tipos de interpretação, de modo a fortalecer tanto o consenso da pesquisa sobre qualidade de interpretação quanto destacar as características específicas de qualidade de determinados domínios da profissão.

\section{Questões conceituais}

Partindo do pressuposto, compartilhado por um número crescente de estudiosos dos Estudos da Interpretação, de que há algo a se ganhar ao assumirmos uma visão compreensiva, unificadora sobre a interpretação, antes de nos concentrarmos em um determinado domínio para pesquisas específicas, definirei interpretação como um espectro conceitual de diferentes (proto)tipos de atividades. Não obstante, ao uso de termos estabelecidos no título e no resto deste artigo, é importante ressaltar que a interpretação de conferência e a interpretação comunitária não são compreendidas como uma dicotomia, mas como áreas diferentes ao longo de um espectro que vai da interpretação em uma esfera de interação internacional, entre representantes de entidades baseadas em diferentes ambientes nacionais ou multinacionais, à interpretação em uma instituição de uma determinada sociedade ou comunidade social, entre indivíduos e representantes daquela instituição.

Cad. Trad., Florianópolis, v. 41, $\mathbf{n}^{0}$ esp. 2, p. 354-384, ago/dez, 2021. 357 
Uma visão panorâmica da profissão de intérprete hoje - e de pesquisas sobre questões de qualidade - resulta em uma imagem bastante desigual. Ainda que uma quantidade considerável de trabalhos já tenha sido realizada sobre interpretação simultânea ou de conferência, a qualidade da interpretação em ambientes intrassociais tem recebido apenas uma atenção acadêmica esporádica. Portanto, aproveitarei principalmente a literatura sobre qualidade em interpretação de conferência (por exemplo, Gile 1991, MoserMercer 1996, Shlesinger 1997, Kahane 2000) para um esboço das suposições e ideias básicas relacionadas às perspectivas de avaliação e aos critérios de qualidade que podem ser aplicados ao longo de todo o espectro da atividade de interpretação.

\subsection{Perspectivas sobre a Qualidade}

Quando pesquisas empíricas sobre critérios de qualidade em interpretações de conferência surgiram, no final dos anos 1980, uma distinção foi feita entre a avaliação da qualidade do ponto de vista dos próprios intérpretes em oposição à qualidade "vista" pelos ouvintes ("usuários"). Como revisado por Kurz, o estudo das expectativas dos usuários se desenvolveu em uma linha de pesquisa bastante produtiva que apontou para algumas variabilidades nas expectativas de qualidade de diferentes grupos de usuário, bem como para algumas discrepâncias nas atitudes de participantes no papel de ouvinte (receptor do texto-alvo) e de falante (produtor do texto-fonte).

Gile (1991) modelou a "configuração de comunicação" como incluindo não apenas o intérprete e os usuários nos papéis de "Remetente" e "Receptor", mas também a posição do "Cliente" ou empregador que comissiona e paga pelos serviços do intérprete. Outros autores adicionaram à gama de potenciais avaliadores da qualidade de interpretação: o(s) colega(s) do intérprete; associados ou representantes do cliente ou usuários; além de pessoas com interesse analítico ou de pesquisa (cf. Pöchhacker 123, Moser-Mercer 46). A última categoria mencionada é usada por Viezzi (12) para uma distinção mais geral entre as perspectivas dos intérpretes e dos

Cad. Trad., Florianópolis, v. 41, $\mathbf{n}^{0}$ esp. 2, p. 354-384, ago/dez, 2021. 358 
usuários (ouvintes, falantes), como discutido acima, e a perspectiva do observador externo que assume uma abordagem de pesquisa em relação à interpretação e que está interessado em mensurar as características "objetivas" do produto textual. Como é igualmente possível, é claro, tentar "medir" as atitudes e julgamentos subjetivos, pode ser útil tentar modelar as relações entre as várias posições e perspectivas como mostrado na Figura $1^{2}$.

Figura 1 - Perspectivas sobre qualidade na interpretação

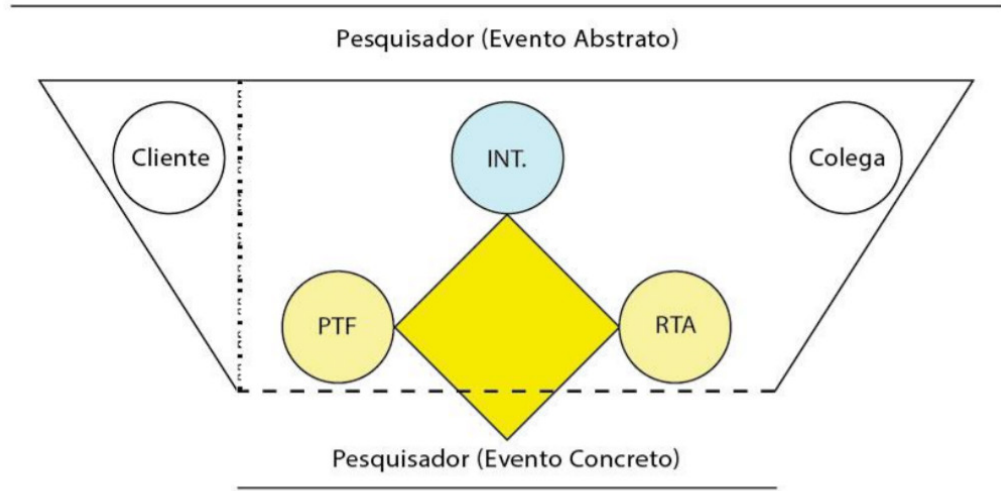

= Evento Comunicativo; PTF = Produtor do Texto Fonte; RTA = Receptor do Texto Alvo

A constelação central das partes em interação envolvidas diretamente no evento comunicativo de produção/recepção do texto é retratada (dentro de um retângulo) como a tríade composta por intérprete (INT.), falante (PTF) e ouvinte (RTA), os papéis do Cliente (empregador) e do Colega (colega intérprete/membro da

\footnotetext{
${ }^{2}$ N. de T.: As traduções das figuras aqui utilizadas estão disponíveis em Barbosa (27). Barbosa, Diego Maurício. Omissões na interpretação simultânea de conferência: língua portuguesa - língua brasileira de sinais. 2014. Universidade Federal de Santa Catarina, dissertação. https://repositorio.ufsc.br/xmlui/ handle/123456789/132401
}

Cad. Trad., Florianópolis, v. 41, $\mathbf{n}^{0}$ esp. 2, p. 354-384, ago/dez, 2021. 359 
equipe) aparecem como posições adicionais a partir das quais a qualidade de interpretação pode ser avaliada.

Além de resumir as múltiplas perspectivas sobre qualidade, a Figura 1 visa ressaltar duas distinções analíticas importantes subjacentes ao estudo da qualidade na interpretação. Primeiramente, o observador externo pode investigar as atitudes, as necessidades e os pontos de vista (normas) dos diversos atores, seja externo, em relação a um evento abstrato (hipotético ou experienciado anteriormente) ou com referência a um evento comunicativo concreto em uma dada situação de comunicação. O último implica um acesso mais direto ao evento comunicativo por parte do pesquisador, que é representado na Figura 1 não pela linha contínua, mas pela linha pontilhada que separa o pesquisador da constelação das partes envolvidas e pela realidade externa de pelo menos parte do produto textual. Em segundo lugar, portanto, a pesquisa sobre qualidade em um evento concreto de interpretação pode se concentrar tanto no produto registrável quanto no processo geral de interação comunicativa. Ambas as perspectivas - orientada ao produto e orientada à interação - são de fundamental importância também para os padrões de qualidade e critérios de avaliação.

\subsection{Padrões e Critérios de Qualidade}

Apesar do fato de que a qualidade na interpretação pode ser avaliada de formas diferentes, a partir de várias perspectivas subjetivas, e que está, portanto, essencialmente no olho de quem vê, há um consenso considerável na literatura sobre uma série de critérios que entram em jogo quando se avalia a qualidade da interpretação. Embora a terminologia possa variar de um autor ou texto para outro, conceitos como precisão, clareza ou fidelidade são invariavelmente considerados essenciais. Esses critérios fundamentais da qualidade de interpretação estão associados à perspectiva orientada ao produto e se concentram principalmente na interpretação ou no texto de chegada como "uma imagem "fiel'" (Gile 198) ou uma "reprodução exata e fiel" (Jones 5) do

Cad. Trad., Florianópolis, v. 41, $\mathbf{n}^{0}$ esp. 2, p. 354-384, ago/dez, 2021. 360 
discurso original. A noção de clareza (ou de aceitabilidade linguística, de correção estilística etc.), por sua vez, refere-se a um segundo aspecto da qualidade, que poderia ser descrito de forma mais geral como "orientado ao ouvinte" ou compreensibilidade do texto de chegada.

Além dessa perspectiva textual dupla, isto é, análise "intertextual" e "intratextual" (Shlesinger 128), espera-se essencialmente que o intérprete "represente integralmente" o falante, seus interesses e suas intenções (cf. Gile 198), daí o critério de efeito equivalente tal como formulado por Déjean Le Féal (155) para a interpretação simultânea. Finalmente, o foco da avaliação de qualidade pode não estar no texto-fonte nem na compreensão dos ouvintes ou nas intenções dos falantes, mas no processo de interação comunicativa como tal. A partir dessa perspectiva, que evidencia a (inter) atividade da interpretação e não sua natureza como uma tarefa de processamento de texto (cf. Wadensjö $21 \mathrm{ff}$ ), qualidade significa essencialmente uma "comunicação bem-sucedida" entre as partes envolvidas em um contexto de interação específico, a julgar a partir das várias perspectivas (subjetivas) no e sobre o evento comunicativo (cf. Gile 193ff) e/ou como analisado mais intersubjetivamente a partir da posição de um observador.

Como indicado acima, os vários conjuntos de critérios subjacentes à avaliação da qualidade na interpretação dizem respeito a diferentes aspectos ou mesmo concepções da tarefa do intérprete, indo desde o processamento de texto à ação comunicativa para um determinado fim e efeito e, mais geralmente, para a função sistêmica de facilitar a interação comunicativa. Como ilustrado na Figura 2, o modelo de padrões de qualidade que vão desde um núcleo léxico-semântico até uma esfera sociopragmática de interação pode ser visto como reflexo da dualidade fundamental da interpretação como um serviço para permitir a comunicação e como uma atividade de produção de texto (cf. Viezzi 40). 
Figura 2 - Padrões de qualidade para o produto e serviço de interpretação

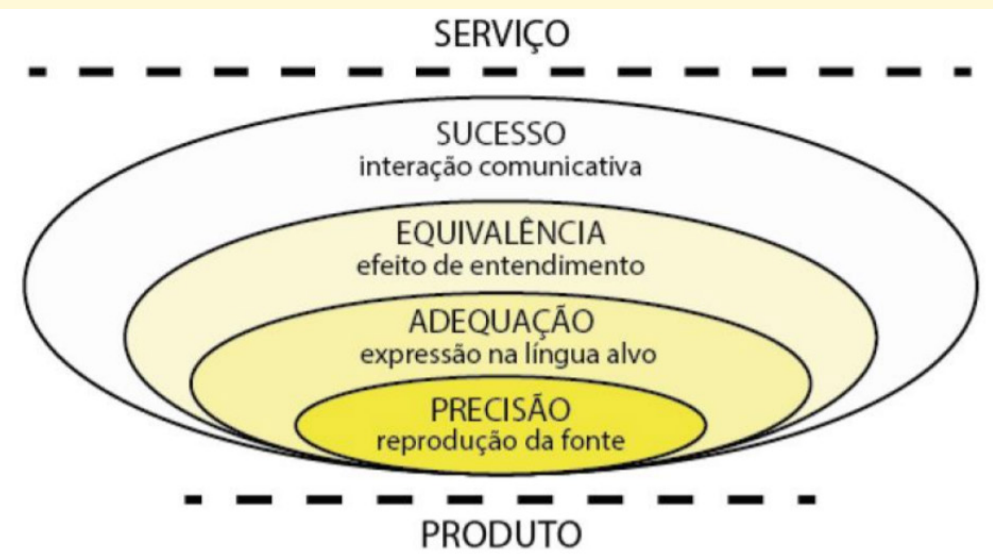

Dadas as múltiplas perspectivas e dimensões modeladas acima, há uma ampla gama de abordagens metodológicas para o estudo da qualidade na interpretação. A seção seguinte trará um panorama dos métodos e dos tópicos de pesquisa relacionados à qualidade com referência à interpretação tanto em conferência quanto em ambientes comunitários. Seguindo a ideia básica deste artigo, farei referência a pesquisas sobre todo o espectro da atividade de interpretação. No entanto, dado que a qualidade da interpretação de conferência já foi revista em outras publicações (por exemplo, Viezzi 1996, Shlesinger 1997, Kahane 2000), a maior parte da atenção e do espaço será dedicada à apresentação de pesquisas sobre qualidade em domínios de base comunitária.

\section{Abordagens metodológicas}

Estudos empíricos sobre a qualidade na interpretação já foram realizados ao longo de várias linhas metodológicas, sendo que as pesquisas de opinião são as mais populares e produtivas.

Cad. Trad., Florianópolis, v. 41, $\mathrm{n}^{0}$ esp. 2, p. 354-384, ago/dez, 2021. 362 


\subsection{Pesquisa de opinião}

Pesquisas de opinião com base em questionários ou entrevistas estruturadas visando uma ou mais posições na constelação da interação comunicativa (cf. Fig. 1) foram conduzidas tanto a partir da perspectiva genérica, frequentemente referindo-se à tarefa do intérprete como tal, quanto no que se refere a eventos concretos de interpretação.

\section{Intérpretes}

Se o ato de interpretar é visto em sua dualidade como um serviço, prestado por um indivíduo (ou grupo, equipe etc.) e como um produto textual, a questão da qualidade pode ser formulada como "O que caracteriza um bom intérprete?" e "O que caracteriza uma boa interpretação?". Essas questões genéricas foram feitas em pesquisas de opinião realizadas com intérpretes e/ou usuários da interpretação desde a década de 1980. Na Austrália, Hearn et al. (1981) consultaram um total de 65 intérpretes em uma avaliação de dois serviços regionais de interpretação. Uma das 65 questões abordadas em entrevistas pessoais focou nas qualificações de um bom intérprete e resultou em critérios tais como conhecimento de ambas as línguas e da cultura do migrante, objetividade, habilidades sociocomunicativas, confiabilidade, responsabilidade, honestidade, educação e humildade (Hearn et al. 61). Os intérpretes também foram questionados sobre sua percepção das atitudes e das expectativas predominantes entre seus clientes, especialmente em relação à definição e à aceitação do papel e da tarefa do intérprete. Uma pergunta separada abordou o assunto da mediação cultural, que tem sido a principal preocupação daqueles que refletem sobre o papel do intérprete comunitário e que também foi abordada na pesquisa de Mesa descrita mais abaixo.

Em seu estudo piloto entre intérpretes de conferência, Bühler pediu a 47 intérpretes de conferência avaliarem a importância relativa de critérios como resistência, equilíbrio, aparência agradá-

Cad. Trad., Florianópolis, v. 41, $\mathbf{n}^{0}$ esp. 2, p. 354-384, ago/dez, 2021. 363 
vel, confiabilidade e capacidade de trabalhar em uma equipe, na visão dos intérpretes. Mais ou menos na mesma época, 39 membros da região alemã da Associação Internacional de Intérpretes de Conferência (AIIC) foram entrevistados sobre problemas de sua profissão e uma longa lista de pré-requisitos emergiu para ser considerado um bom intérprete e membro de equipe, abrangendo de conhecimento linguístico e geral à qualidade da voz, e de boa saúde e resistência a qualidades psicossociais como aparência, equilíbrio, polidez e flexibilidade (cf. Feldweg 326-378).

\section{Usuários}

Impulsionada pela tentativa de Bühler de generalizar, com base em suas descobertas, as necessidades e as expectativas de usuários (ouvintes), pesquisas de opinião baseadas em questionários sobre as expectativas de usuários foram introduzidas por Kurz e transformadas em uma linha de pesquisa altamente produtiva (cf. Kurz). Enquanto algumas das pesquisas de opinião com usuários tenham limitado o foco para os critérios de Bühler, relativos ao produto ("linguístico"), particularmente para a interpretação simultânea, outros o ampliaram para incluir aspectos do papel dos intérpretes e as especificidades da interpretação consecutiva e os tipos específicos de reuniões (cf. Kopczynski 1994, Marrone 1993, Vuorikoski 1993). Uma distinção significativa foi feita por Kopczynski entre as preferências de usuários como falantes em oposição aos ouvintes em um ambiente de conferência. Enquanto aqueles tolerariam maior grau de intervenção por parte do intérprete, estes mostrariam uma preferência mais forte pelo papel fantasma do intérprete e favoreceriam uma produção mais próxima das palavras do falante, e até mesmo dos erros, do falante (cf. Kopczynski 195ff).

$\mathrm{Na}$ interpretação comunitária, em que a interpretação consecutiva bilateral curta (liaison) de diálogo é de longe o modo mais comum, a distinção entre os dois papeis de usuários é de natureza diferente. Enquanto as principais partes envolvidas normalmente 
se revezarão para falar e ouvir, elas são essencialmente diferentes em seu status como representantes em oposição a clientes de uma instituição ou serviço público. Logo, é comum fazer referência a prestadores de serviços ou profissionais de um lado e a clientes não-falantes-(de-língua-majoritária) de outro. Ambas as perspectivas de usuários - bem como aquela dos intérpretes - foram investigadas por Mesa, que aplicou questionários a 66 clientes (em 11 línguas diferentes) e a 288 profissionais da saúde de 30 instituições diferentes na região de Montréal. Enquanto aqueles foram questionados sobre sua percepção da qualidade dos serviços de interpretação recebidos (vide abaixo), estes foram solicitados a avaliarem a importância de mais de 30 características e comportamentos de intérpretes em uma escala de três pontos (très important [muito importante] - assez important [bastante importante] - peu important [pouco importante]). Na pesquisa sobre expectativas dos prestadores de serviço, os itens que receberam as maiores notas (muito importante) da maioria dos participantes incluíram "entende completamente a língua do cliente" (96\%), "garante a confidencialidade" (95\%), "aponta a falta de compreensão do cliente" (92\%), "se abstém de julgamentos" (91\%) e "traduz fielmente" (90\%). De maneira chocante, no entanto, a expectativa de que o "intérprete cultural" geralmente "explique valores culturais" classificou-se abaixo das expectativas dos prestadores de serviços (61\% muito importante) e ainda menos participantes (47\%) consideraram muito importante receber explicações culturais do intérprete após o intercâmbio mediado.

As expectativas dos prestadores de serviço sobre o que intérpretes devem fazer em vários ambientes institucionais também foram investigadas em duas pesquisas baseadas em questionários conduzidas em Viena. Pöchhacker (2000) coletou respostas de 629 assistentes sociais e profissionais da saúde sobre a qualificação e a definição de papeis dos intérpretes. De 10 critérios, como competência linguística e cultural, educação geral, conhecimento especializado, treinamento em interpretação, comportamento absolutamente neutro, além de discrição e confidencialidade, apenas 
os dois últimos foram classificados como "muito importantes" (em uma escala de três pontos) pela maioria dos participantes. Contudo, as expectativas dos usuários entre esses prestadores de serviço eram altamente exigentes. Mais de dois terços dos participantes consideraram parte da tarefa do intérprete funções de edição do discurso, tais como simplificações e explicações das declarações dos prestadores de serviço e resumo das declarações do cliente, e $62 \%$ também esperavam que os intérpretes explicassem referências e significados culturais e que formulassem declarações autônomas quando solicitado pelo prestador de serviço. Uma análise dos dados por grupos profissionais (médicos, enfermeiros, terapeutas, assistentes sociais) produziu uma série de diferenças significativas. Assim, enfermeiros tenderam a compreender o papel do intérprete de maneira muito mais ampla do que médicos, enquanto assistentes sociais demostraram uma aceitação muito maior do papel do intérprete como mediador cultural. Tal como demonstrado no estudo realizado por Mesa, os próprios intérpretes hospitalares acreditavam, muito mais veementemente do que a equipe da saúde, que era sua obrigação fornecer explicações culturais como parte de seu trabalho ( $83 \%$ versus $59 \%$ ).

Kadric usou uma abordagem semelhante, baseada em questionários, para averiguar as expectativas dos usuários em relação às qualificações e à definição de tarefas de intérpretes judiciais. Sua população-alvo consistiu em aproximadamente 200 juízes de tribunais locais em Viena. Em relação às qualificações, os 133 participantes classificaram "habilidades de interpretação", seguido de "competência linguística e cultural” em um nível mais alto do que "conhecimento jurídico básico" e "conhecimento da organização e dos procedimentos do tribunal". Ao serem questionados sobre sua definição da tarefa do intérprete, os juízes acabaram sendo menos restritivos do que se esperaria com base na literatura (cf. Morris), mostrando aceitação considerável quanto aos resumos (46\%), à simplificação das declarações do juiz (63\%), à explicação da linguagem jurídica $(72 \%)$ e, até mesmo, à formulação de perguntas de rotina e advertências em nome do juiz (72\%). Aproximadamen-

Cad. Trad., Florianópolis, v. 41, $\mathrm{n}^{0}$ esp. 2, p. 354-384, ago/dez, 2021. 366 
te, $85 \%$ dos participantes esperavam que o intérprete explicasse referências culturais ao tribunal.

Posto que os juízes de tribunais locais pesquisados por Kadric também são responsáveis por contratar intérpretes quando necessário, o estudo é único na medida em que também aborda a perspectiva do cliente no sentido mais amplo do termo, conforme descrito abaixo.

\section{Clientes}

Na literatura sobre interpretação comunitária, o papel de cliente, geralmente, se refere ao cliente individual da instituição ou serviço público, e, portanto, ao indivíduo intérprete em oposição ao cliente profissional da troca comunicativa. Em um sentido mais geral, no entanto, o cliente do intérprete também deve ser visto como o indivíduo ou instituição que comissiona - e paga por - seus serviços (cf. Fig. 1). Não obstante o papel central do cliente - no sentido de empregador - na constelação de interpretação como um serviço profissional, as expectativas de qualidade associadas com essa posição receberam muito pouca atenção. O estudo de Kadric sobre interpretação em tribunal ${ }^{3}$ aponta para especificidades dessa perspectiva sobre qualidade ao investigar "critérios de recontratação", como "facilitação da comunicação sem problemas" e levantar preocupações adicionais como custos e taxas (cf. Kadric 126-136).

$\mathrm{Na}$ área de interpretação de conferência, uma grande pesquisa sobre qualidade de interpretação, a partir da perspectiva do empregador, foi realizada pelo Serviço Conjunto de Interpretação de Conferências da Comissão Europeia, o maior cliente de serviços de interpretação do mundo. Não é surpreendente, então, que adicione

\footnotetext{
${ }^{3}$ N. de T.: No Brasil, podemos também encontrar na literatura o termo interpretação judicial. Para mais informações sobre o uso dos termos interpretação jurídica (em inglês, legal interpreting) e interpretação judicial (em inglês, court interpreting), conferir: Santos, Silvana Aguiar dos; Sutton-Spence, Rachel. A profissionalização de intérpretes de línguas de sinais a esfera jurídica. Translatio, n. 15, 2018, pp. 264-289. https://seer.ufrgs.br/translatio/article/view/80945/48554.
}

Cad. Trad., Florianópolis, v. 41, $\mathrm{n}^{0}$ esp. 2, p. 354-384, ago/dez, 2021. 367 
considerações de custo e administração à lista de preocupações relacionadas à qualidade e assim aborde a dimensão do serviço bem como aquela de intérpretes individuais e seu trabalho (cf. Kahane).

\section{Pesquisas com base em Casos}

Além de pesquisas concebidas para obter opiniões e expectativas normativas em relação a uma noção mais ou menos abstrata sobre interpretação e sobre intérpretes, pesquisas de opinião também foram conduzidas tendo como referência a qualidade em eventos concretos de interpretação de conferência (cf. Kurz). Para ambientes de interpretação comunitária, um método de pesquisa de opinião cumulativo com base em casos foi desenvolvido e aplicado por um serviço cultural canadense de interpretação (Garber e Mauffette-Leenders). Foram recebidos 34 feedbacks de clientes não falantes de inglês em três grupos linguísticos (vietnamita, polonês e português) por meio de questionários traduzidos distribuídos por 17 intérpretes em um total de 72 tarefas. Entre outras coisas, foi requisitado aos clientes avaliarem a compreensibilidade em uma escala de seis pontos e manifestarem sua percepção sobre a qualidade da interpretação tendo como referência critérios como precisão e imparcialidade. Um formulário de avaliação mais elaborado foi usado para prestadores de serviço nos mesmos encontros, implementando assim um sistema de garantia de qualidade cobrindo as perspectivas tanto do cliente individual quanto do prestador de serviço. A pesquisa de opinião de Mesa, supramencionada, fez uma distinção semelhante entre a perspectiva do cliente individual e a do prestador de serviço. Enquanto foi solicitado aos 66 clientes (de 11 línguas diferentes) que expressassem sobretudo sua concordância (ou discordância) com 10 declarações avaliativas sobre características de desempenho do intérprete, foi requisitado aos prestadores de serviço que complementassem suas classificações genéricas de expectativas de usuário declarando até que ponto ("sim" - "mais ou menos" - "não") eles tinham considerado que os membros do serviço de interpretação em estudo tinham de fato cumprindo tais expectativas.

Cad. Trad., Florianópolis, v. 41, $\mathrm{n}^{0}$ esp. 2, p. 354-384, ago/dez, 2021. 368 
Se as expectativas de usuários e a percepção e a avaliação de qualidade em encontros reais podem ser duas coisas diferentes, é preciso ainda tentar avaliar a realidade subjacente a julgamentos subjetivos sobre um produto de interpretação específico (cf. também Gile 68). Uma tentativa interessante de fazer isso é o estudo (experimental) realizado por Strong e Fritsch Rudser sobre a avaliação subjetiva de intérpretes de língua de sinais. Usando um simples instrumento de pesquisa de opinião (formulário de avaliação) com itens como a habilidade linguística do intérprete, além da qualidade geral (gosto - não gosto) e compreensibilidade da interpretação, seis participantes surdos e seis ouvintes avaliaram passagens de interpretações (para a língua de sinais e para o inglês, respectivamente) por parte de 25 intérpretes com diferentes níveis de habilidades. A confiabilidade entre participantes foi constatada como elevada, embora não tão alta quanto o consenso entre participantes sobre os resultados de precisão proposicional usados como uma medida de avaliação objetiva. Strong e Fritsch Rudser (11) consideram que suas descobertas sugerem que "enquanto as avaliações subjetivas fornecem uma dimensão interessante e útil de avaliação do intérprete, elas não devem substituir uma medida objetiva sólida".

Esse exemplo aponta para a necessidade de analisar a realidade subjacente a julgamentos avaliativos para superar as limitações metodológicas da pesquisa observacional interativa, particularmente o risco de um viés pessoal ou contextual sistêmico nas respostas (cf. Gile 74). Já que essa realidade é principalmente a produção do intérprete ou seu texto de chegada (em um sentido amplamente semiótico), pesquisas observacionais não reativas tem se concentrado principalmente na análise e na avaliação de dados linguístico-textuais. Enquanto esse tipo de abordagem pudesse ser adotado para pressupor o uso de dados autênticos à medida que eles ocorrem em campo, análises linguístico-textuais têm sido desenvolvidas e aplicadas sobretudo em estudos experimentais, com critérios como precisão e adequação (cf. Fig. 2) servindo como variáveis dependentes no projeto da pesquisa.

Cad. Trad., Florianópolis, v. 41, $\mathrm{n}^{0}$ esp. 2, p. 354-384, ago/dez, 2021. 369 


\subsection{Experimentação}

\section{Medidas de desempenho}

Desde a década de 1960, estudos experimentais sobre interpretação (simultânea) tem demostrado um profundo interesse sobre o impacto de vários parâmetros de input $t^{4}$ (por exemplo, velocidade, ruído) sobre o desempenho do intérprete. Ainda que experimentos não abordem explicitamente a questão da qualidade como tal, observar intérpretes e o "quão bem eles se saem sob circunstâncias específicas" certamente está ligado à avaliação da qualidade ou pelo menos com um aspecto específico dela. De fato, muitos experimentos foram idealizados de maneira a aferir o parâmetro presumivelmente essencial de precisão. Contagens de erro (por exemplo, Barik), notas sobre informatividade bem como de compreensibilidade (Gerver), vários tipos de resultados de precisão proposicionais - ou verbais - (por exemplo, Mackintosh 1983, Tommola e Lindholm 1995, Lee 1999a) e até mesmo padrões de sincronicidade acústica (Lee 1999b, Yagi 1999) já foram usados, com mais ou menos confiança, como medidas objetivas relativas ao desempenho de interpretação em ambientes experimentais. Somente alguns autores reconhecem explicitamente que seus parâmetros textuais pontuáveis abrangem apenas certo aspecto de qualidade, se é que refletem qualidade em algum momento. Mackintosh (15), por exemplo, que usou um sistema semântico complexo de pontuação e calculou a confiabilidade entre três juízes, afirmou claramente: "em qualquer exercício projetado para permitir uma avaliação qualitativa de produtos de interpretação, seria necessário refinar o sistema de pontuação". Um reconhecimento semelhante das limitações de seu sistema de codificação de erros é formulado por Barik (207): "tampouco o sistema visa refletir, exceto de uma ma-

\footnotetext{
${ }^{4}$ N. de T.: No Brasil, se utiliza os termos entrada ou insumos ou recepção da informação como tradução para o termo input, porém o termo em inglês é utilizado mais comumente.
}

Cad. Trad., Florianópolis, v. 41, $\mathrm{n}^{0}$ esp. 2, p. 354-384, ago/dez, 2021. 370 
neira muito grosseira, sobre a adequação ou a qualidade de uma interpretação, pois outros fatores críticos como características de entrega - entonação de voz, adequação de pausas etc. - não são levados em consideração". Esse problema permanece sem solução, como declarado recentemente por Gile: "[...] ainda que possa haver consenso intersubjetivo sobre grandes diferenças na qualidade da interpretação, em níveis mais sutis, a comunidade de pesquisa sobre interpretação ainda está tateando no escuro e não encontrou uma métrica válida, sensível e confiável para aferir o desempenho do intérprete" (Gile apud Niska 120).

Uma maneira de superar as limitações metodológicas de experimentações tradicionais é o uso de (alguma característica da) qualidade não como a variável dependente, mas como variável experimental de input.

\section{Qualidade como variável de input}

Ao contrário da aferição de aspectos de qualidade relacionados à precisão, supramencionados, estudos envolvendo a manipulação de características de qualidade de saída no desenho experimental tendem a se concentrar na dimensão da adequação do texto de chegada para um público específico. Essa abordagem de experimentação na interpretação foi iniciada por Berk-Seligson em sua pesquisa sobre interpretação judicial. A pesquisadora apresentou, a um grupo de júri simulado, duas versões diferentes do depoimento da testemunha proferido pelo intérprete judicial e conseguiu demostrar que variações de registro (polidez) afetarão significativamente a maneira como ouvintes percebem e julgam a credibilidade do falante, nesse caso uma testemunha.

$\mathrm{Na}$ área de interpretação simultânea de conferência, dois estudos inovadores se concentraram precisamente na característica que se descobriu ser relativamente sem importância em uma série de estudos sobre expectativa do usuário. Shlesinger apresentou a ouvintes duas versões de um texto de chegada, um entregue com o que ela classificou como entonação interpretativa, e a outra lida com ritmo, ênfa-

Cad. Trad., Florianópolis, v. 41, $\mathbf{n}^{0}$ esp. 2, p. 354-384, ago/dez, 2021. 371 
se e padrões prosódicos ideais. Em um teste de compreensão e memória administrado para seus dois grupos de participantes, o grupo que ouviu a versão com entonação padrão deu respostas $20 \%$ mais corretas do que o grupo que ouviu a versão com interpretação. Em outro experimento sobre o impacto da entonação, Collados Ais produziu três versões diferentes em entonação e/ou informação de um discurso (simulado) de conferência e pediu que usuários experientes de interpretação simultânea julgassem a qualidade da interpretação com a ajuda de um questionário. Ainda que os mesmos participantes tenham confirmado a relativa insignificância de características não verbais em uma pesquisa anterior sobre expectativas de usuários, sua avaliação direta da qualidade da interpretação (simulada) e do intérprete demonstraram um impacto significativo da entonação monótona no material experimental de input.

Cada um dos estudos, mencionados acima, considerou a qualidade em termos do efeito cognitivo ou pragmático da interpretação sobre os leitores, abordando assim o critério de efeito equivalente como formulado por Déjean Le Féal (155). Em termos metodológicos, esses experimentos também compartilham o uso da simulação como uma característica fundamental em seu projeto de pesquisa e assim conseguem superar algumas das limitações de experimentos de laboratório em que, por definição, a maioria das variáveis de um ambiente comunicativo autêntico permanece fora de vista e em que a ausência de um usuário ou de um cliente invariavelmente deixa sem resposta a questão "qualidade (adequação) para quem?".

Enquanto esses estudos orientados ao efeito funcionam sem a análise de dados linguístico-textuais, experimentação orientada ao desempenho é tradicionalmente associada com o processamento de gravações e transcrições (frequentemente chamados de protocolos) da produção verbal do intérprete. Em termos bastante gerais, tais análises de corpora textuais gerados experimentalmente poderiam ser chamadas de observações baseadas em corpus. Para a presente discussão, no entanto, uma distinção será feita entre essas observações secundárias (análise) de dados a partir de um ambiente experimental controlado e as pesquisas observacionais no sentido

Cad. Trad., Florianópolis, v. 41, $\mathrm{n}^{0}$ esp. 2, p. 354-384, ago/dez, 2021. 372 
original de se trabalhar com dados de ocorrência natural na área. Trabalhar com corpora autênticos será discutido aqui, portanto, como mais outra abordagem metodológica para o estudo da qualidade na interpretação.

\subsection{Observação Baseada em Corpus}

Em comparação com o volume de trabalho realizado com base em pesquisas de opinião e experimentos, a literatura sobre qualidade de interpretação contém apenas alguns poucos estudos observacionais baseados em corpus. Cokely, por exemplo, analisou "equívocos dos intérpretes" em um corpus de 10 interpretações autênticas de língua de sinais em um ambiente de conferência, Pöchhacker descreveu características relacionadas à qualidade da superfície do texto, tais como interferência, hesitação, erros e deslizes, bem como problemas de coerência em cinco pares de discursos originais e interpretações, e Kalina lista análise de produto em corpora autênticos e também experimentais como a base metodológica de uma dúzia de estudos empíricos, incluindo pesquisas sobre assuntos como entonação, interferência, erros e autocorreções.

Como fica evidente, a partir dos exemplos acima, os resultados da análise de um corpus autêntico de dados textuais estão sujeitos ao mesmo tipo de limitação que os estudos experimentais, discutidos acima, isto é, o pesquisador terá uma visão de apenas um conjunto de características ou uma dimensão da qualidade, em vez de ter uma avaliação da qualidade como tal. Para começar, o uso de transcrições obviamente trunca e distorce o produto textual semioticamente complexo que está sendo estudado. Além disso, pelo menos na área de interpretação de conferência, houve um forte viés a favor de características textuais distintas e quantificáveis, tais como erros, omissões etc., com pouco ou nenhum respeito por relações e efeitos psico-comunicativos complexos.

Na literatura sobre interpretação comunitária, há pouquíssimos exemplos de análise quantitativa de corpora textuais (por exemplo, Ebden et al.). Ao contrário, o tema - não necessariamente de

Cad. Trad., Florianópolis, v. 41, $\mathbf{n}^{0}$ esp. 2, p. 354-384, ago/dez, 2021. 373 
qualidade - tem sido tratado principalmente em uma base qualitativa, em particular com o uso de métodos analíticos do discurso (por exemplo, Rehbein 1985, Roy 1993, Mason 1999). A aplicação desses métodos de pesquisa especificamente à questão da qualidade entrou no debate apenas recentemente, e há uma consciência nítida de que apenas estudos observacionais baseados em corpora textuais autênticos serão insuficientes para a tarefa de avaliar a qualidade de interpretação em interações comunicativas concretas.

\subsection{Estudo de caso}

Partindo do pressuposto de que a qualidade é um fenômeno sociopsicológico multidimensional, bem como um fenômeno textual inserido em um contexto institucional e situacional específico de interação, pode-se argumentar que métodos que permitem que o pesquisador colete o máximo de informações sobre um único caso são mais úteis para o estudo observacional de qualidade. Esse conceito de estudo de caso (cf. Robson 5), que naturalmente se presta à combinação de várias técnicas observacionais, não tem sido muito comum nas pesquisas sobre interpretação, até o momento.

Para pesquisas sobre qualidade de interpretação, o projeto do estudo de caso sugeriria combinar observações com base em corpus, pesquisas de opinião (entrevistas), observação participante e análise documental para garantir uma visão holística sobre a qualidade também a nível do efeito pretendido e da interação bem-sucedida, e há algumas iniciativas em que várias ou todas estas abordagens metodológicas são explicitamente tomadas. Gile, por exemplo, usou um questionário e relatou suas impressões de qualidade de produção textual, mas não se envolveu em análises sistemáticas de corpus nem discutiu sua abordagem como um observador participante. De maneira similar, Marrone utilizou um questionário, mas não considerou a análise de corpus. Como ele próprio estava envolvido no caso, no papel de intérprete (consecutivo), ele colocou um observador "para monitorar eventos à luz dos parâmetros do questionário” (Marrone 36), mas não relatou

Cad. Trad., Florianópolis, v. 41, n $^{0}$ esp. 2, p. 354-384, ago/dez, 2021.374 
qualquer dado dessa fonte. Pöchhacker, em seu estudo de caso de conferência, utilizou a análise de dados baseada em corpus, notas de observador participante e análise documental, mas não conseguiu ter acesso suficiente a participantes da conferência com sua pesquisa de avaliação pelo usuário. O exemplo mais bem-sucedido do uso de pesquisa de estudo de caso na interpretação é, provavelmente, o trabalho de Wadensjö, que gravou e analisou um grande corpus de discurso autêntico, participou dos eventos interpretados, como observadora, e conduziu entrevistas pós-interação. Dada sua orientação claramente descritiva, Wadensjö evita, em grande parte, discutir seus dados em termos de qualidade. Por outro lado, ela discute as perspectivas de aplicação de sua abordagem metodológica a "toda a questão de avaliação da (o grau de) habilidade profissional de intérpretes" (Wadensjö 286).

\section{4. "Qualidade em todas as áreas"?}

Considerando o contexto das dimensões conceituais e das abordagens metodológicas revisadas, neste artigo, a questão da qualidade e de como avaliá-la se destaca como um problema de pesquisa particularmente complexo. Aqueles que avaliariam a qualidade da interpretação em todas as áreas enfrentam o fato de que a interpretação não é um fenômeno invariável único, mas uma atividade (mais ou menos profissionalizada) que assume diferentes formas em diferentes contextos. Portanto, o conceito de qualidade não pode ser atribuído a algum substrato linguístico, mas deve ser visto também no nível de seu efeito e de seu impacto comunicativo no âmbito de limitações situacionais e institucionais específicas. Nas palavras de Wadensjö (287): "na prática, não existem critérios absolutos e inquestionáveis para definir um modo de interpretação que seria 'bom' em qualquer situação. Tipos diferentes de atividades com estruturas de objetivos diferentes, bem como diferentes preocupações, necessidades, desejos e compromissos de partes principais implicam várias exigências sobre os intérpretes”.

Cad. Trad., Florianópolis, v. 41, $\mathrm{n}^{0}$ esp. 2, p. 354-384, ago/dez, 2021. 375 
Não obstante a essa diversidade na natureza do assunto e da questão em estudo, pesquisadores interessados na avaliação da qualidade em interpretações comunitárias e/ou de conferência têm muito em comum em relação a definições básicas, questões formuladas, métodos utilizados e problemas encontrados.

\subsection{Terreno comum}

Há um consenso na literatura em todo o espectro tipológico que a interpretação, concebida como a tarefa de mediar a comunicação entre as partes envolvidas de diferentes origens linguísticas e culturais é, antes de tudo, um serviço desenvolvido para satisfazer uma necessidade. Ao fornecer esse serviço, o intérprete fornece essencialmente um produto textual que dá acesso à mensagem original do falante, de modo a torná-la significativa e eficaz no âmbito do espaço sociocultural do receptor. Daí a pergunta: tanto em pesquisas de interpretação comunitária quanto de conferência, até que ponto o intérprete é ou deveria ser visto como um mediador cultural? - e até que ponto deve-se esperar que agisse como tal? - e que tipo de interpretação melhor assegurará um acesso preciso e, comunicativamente, adequado àquilo que o falante pretendeu transmitir?

Dadas as múltiplas perspectivas e posições na constelação de interação mediada, essas perguntas podem ser feitas, mais especificamente, a partir de diferentes perspectivas, como os pontos de vista normativos e as expectativas dos usuários quanto ao serviço e ao produto, a definição do próprio intérprete no que concerne sua tarefa, suas qualificações e seus padrões de desempenho, a satisfação do cliente profissional com o serviço prestado etc. Respostas a estas questões vêm sendo buscadas nas áreas de interpretação comunitária e de conferência com um conjunto semelhante de métodos de pesquisa, em particular pela utilização de pesquisas de opinião baseadas em questionários. No que diz respeito às características do produto textual, tanto a observação baseada em corpus da interpretação na área e a experimentação quanto simulações já foram utilizadas, em diferentes níveis, no estudo da

Cad. Trad., Florianópolis, v. 41, $\mathbf{n}^{0}$ esp. 2, p. 354-384, ago/dez, 2021. 376 
qualidade em ambientes comunitários e de conferência. Em ambos os domínios, também existe certo reconhecimento do mérito metodológico de estudos de caso mais aprofundados, combinando a coleta de dados interativos para os critérios de avaliação relacionados mais a serviços com análise textual (de discurso) para aspectos relacionados ao produto.

É verdade, claro, que o terreno comum em estudos orientados à qualidade de interpretação comunitária e de conferência também se estende aos problemas metodológicos enfrentados pelo pesquisador: a dificuldade de obter um número suficiente de respostas a pesquisas de opinião entre usuários; a intrusão da coleta de dados interativos para estudar um fenômeno que frequentemente se espera ser invisível no evento comunicativo do cliente; o problema do viés contextual, quando expectativas abstratas são estudadas no âmbito de eventos interpretados específicos; a delicada questão de observar e avaliar o trabalho de (colegas) profissionais; o acesso limitado a profissionais para estudos experimentais ou simulados; e a falta de parâmetros de produto para usar como um indicador de qualidade confiável. Tudo isso atrapalha a pesquisa empírica sobre modelos de avaliação e sua aplicação. Mesmo assim, não parece ser otimismo excessivo acreditar que todo esse consenso conceitual e metodológico detém considerável potencial para o futuro da pesquisa sobre qualidade na interpretação.

\subsection{Perspectivas futuras}

Posto que a questão da qualidade na interpretação como serviço profissional veio para ficar, pode-se seguramente esperar um fluxo constante de pesquisas sobre o tema, particularmente em domínios comunitários que estão em fase de profissionalização. Contanto que os pesquisadores tenham um interesse ativo em trabalhar com a qualidade, além de sua especialidade tipológica, pode-se esperar uma troca mutuamente enriquecedora sobre as perguntas de pesquisa, modelos conceituais e abordagens metodológicas. Entre os casos potenciais ou mesmo reais de interesse convergente, po-

Cad. Trad., Florianópolis, v. 41, $\mathbf{n}^{0}$ esp. 2, p. 354-384, ago/dez, 2021. 377 
de-se citar a recente preocupação em pesquisa de interpretação de conferência com o impacto de restrições institucionais específicas (cf. Marzocchi), que tem sido um tema importante no estudo da interpretação comunitária. Da mesma forma, a questão do papel do intérprete como mediador cultural (Kopczynski), especialmente na interpretação consecutiva (cf. Marrone), é um tema que pode atrair o interesse de pesquisadores da interpretação de conferência para o domínio comunitário em busca de modelos existentes e de descobertas. O recente apelo de Kahane para que os pesquisadores se interessem mais por especificidades situacionais e que se "amplie o campo, passando de questões puramente linguísticas para questões pragmáticas, de comunicação" é um caso em questão.

Aqueles que se concentram na interpretação comunitária, por sua vez, podem se beneficiar de técnicas para análise linguística quantitativa de dados textuais (por exemplo, Cambridge) e poderiam aplicar ideias de pesquisas sobre interpretação simultânea ao muito negligenciado estudo sobre a interpretação sussurrada ${ }^{5}$ em ambientes comunitários. Em áreas de sobreposição temática considerável, como o caso mencionado de interpretação sussurrada, pode-se provar frutífera a elaboração de projetos de pesquisa comparativa que destaquem tanto o terreno comum quanto as especificidades tipológicas da interpretação em vários domínios. Pode-se, por exemplo, investigar e comparar as dinâmicas e os efeitos da interpretação consecutiva de diálogos em vários âmbitos ou as expectativas dos usuários sobre o papel do intérprete e suas qualificações necessárias. Será que um médico e um pesquisador teriam os mesmos critérios de qualidade e de expectativas sobre intérpretes e interpretações em um congresso médico e em entrevistas com pacientes que falam um outro idioma? Seja qual for a resposta esperada, eu argumentaria que questões como essas deveriam ser, no mínimo, levantadas e submetidas a estudos empíricos.

Como fica evidente, a partir da visão geral apresentada, neste artigo, há uma variedade de ferramentas e de métodos conceituais

${ }^{5} \mathrm{~N}$. de T.: Também conhecida como chuchotage.

Cad. Trad., Florianópolis, v. 41, $\mathrm{n}^{0}$ esp. 2, p. 354-384, ago/dez, 2021. 378 
que pode ser usada para ampliar e refinar abordagens de pesquisa relativas à qualidade na interpretação. Deve ter ficado igualmente claro que estudar a qualidade significa essencialmente fazê-lo sob diferentes ângulos e perspectivas, considerando os aspectos tanto de produto quanto de serviço da atividade de interpretação. Pesquisas de opinião multiperspectivas conduzidas por Mesa, e abordagens multimétodo em geral (por exemplo, Vuorikoski) devem, portanto, provar-se vitais para o estudo da qualidade nos dois lados do espectro tipológico.

\section{Conclusão}

O ponto de partida para o presente artigo de revisão foi o desejo profissional da qualidade em todas as áreas. Daí a ideia de examinar o estado da arte nos Estudos da Interpretação em busca de ferramentas conceituais e metodológicas para o estudo empírico e a avaliação da qualidade em todo o espectro tipológico, indo da interpretação internacional (conferência) até a intrassocial (comunitária). Ao assumir uma visão mais ampla sobre tipos de interpretação, aspectos de qualidade e métodos de avaliação, este artigo visa estabelecer o consenso compartilhado por aqueles que estudam a qualidade na interpretação. Na medida em que consegue fazer isso, espera-se que o artigo possa motivar pesquisadores a olhar além dos horizontes tipológicos e metodológicos de sua especialidade em particular, para que venham a considerar enriquecer seu trabalho ao aprender com o trabalho de seus colegas em outros domínios da interpretação.

Cad. Trad., Florianópolis, v. 41, $\mathbf{n}^{0}$ esp. 2, p. 354-384, ago/dez, 2021. 379 


\section{Referências}

Barik, H. C. "A Description of Various Types of Omissions, Additions and Errors of Translation Encountered in Simultaneous Interpretation". Meta, v. 16, n. 4, 1971, pp. 199-210.

Berk-Seligson, S. "The Impact of Politeness in Witness Testimony: the Influence of the Court Interpreter". Multilingua, v. 7, n. 4, 1988, pp. 411-439.

Bühler, H. "Linguistic (Semantic) and Extra-linguistic (Pragmatic) Criteria for the Evaluation of Conference Interpretation and Interpreters". Multilingua, v. 5, p. 4, 1986, pp. 231-235.

Cambridge, J. Information Exchange in Bilingual Medical Interviews. 1997. University of Manchester, Dissertation.

Cokely, D. Interpretation: A Sociolinguistic Model. Burtonsville, Linstok Press, 1992.

Collados Ais, Á. La evaluación de la calidad en interpretación simultánea. La importancia de la comunicación no verbal. Granada, Editorial Comares, 1998.

Déjean Le Féal, K. "Some Thoughts on the Evaluation of Simultaneous Interpretation". Interpreting - Yesterday, Today, and Tomorrow, editado por D. e M. Bowen, Binghamton NY, SUNY, 1990, pp. 154-160.

Ebden, P., A. Bhatt, O. J. Carey e B. Harrison. "The bilingual consultation”. The Lancet, February 13, 1988 [8581], pp. 347.

Feldweg, E. Der Konferenzdolmetscheriminternationalen Kommunikationsprozeß. Heidelberg, Julius Groos, 1996.

Garber, N. and L. A. "Mauffette-Leenders. Obtaining Feedback from NonEnglish Speakers." The Critical Link: Interpreters in the Community. Editado por: S. E. Carr, R. Roberts, A. Dufour e D. Steyn, Amsterdam and Philadelphia, John Benjamins, 1997, pp. 131-143.

Cad. Trad., Florianópolis, v. 41, $\mathrm{n}^{0}$ esp. 2, p. 354-384, ago/dez, 2021. 380 
Gerver, D. Aspects of Simultaneous Interpretation and Human Information Processing. 1971. Oxford University, Thesis.

Gile, D. «L'évaluation de la qualité de l'interprétation par les délégués : une étude de cas ». The Interpreters' Newsletter, 3, 1990, pp. 66-71.

Gile, D. "A Communication-Oriented Analysis of Quality in Nonliterary Translation and Interpretation”. Translation: Theory and Practice. Tension and Interdependence, editado por M. L. Larson, Binghamton NY, SUNY, 1991, pp. 188-200.

Gile, D. Observational Studies and Experimental Studies in the Investigation of Conference Interpreting," Target, v. 10, n. 1, 1998, pp. 69-93.

Hearn, J. The Unrecognized Professionals, Melbourne, Education Research and Development Committee, 1981.

Hearn, J., T. Chesher e S. Holmes. “An Evaluation of Interpreter Programmes in Relation to the Needs of a Polyethnic Society and the Implications for Education" [Project notes, questionnaire, and summarized responses], Ms., 1981.

Jones, R. Conference Interpreting Explained, Manchester, St. Jerome Publishing, 1998.

Kadric, M. Dolmetschen bei Gericht. Eine interdisziplinäre Untersuchung unter besonderer Berücksichtigung der Lage in Österreich. 7, 2000. Universität Wien, Dissertation.

Kahane, E. Thoughts on the Quality of Interpretation, 2000. http://www.aiic.net/ ViewPage.cfm/page197.htm

Kalina, S. Strategische Prozesse beim Dolmetschen. Tübingen, Gunter Narr, 1998.

Kopczynski, A. "Quality in Conference Interpreting: Some Pragmatic Problems". Translation Studies - An Interdiscipline. Editado por M. Snell-Hornby, F. 
Pöchhacker e K. Kaindl, Amsterdam and Philadelphia, John Benjamins, 1994, pp. 189-198.

Kurz, I. "Conference Interpreting: Quality in the Ears of the User". Meta, v. 46, n. 2, 2001, pp. 394 - 409. https://doi.org/10.7202/003364ar

Lee, T.-H. "Speech Proportion and Accuracy in Simultaneous Interpretation from English into Korean”. Meta, v. 44, n. 2, 1999a, pp. 260-267.

Lee, T.-H. "Simultaneous Listening and Speaking in English into Korean Simultaneous Interpretation". Meta, v. 44, n. 4, 1999b, pp. 560-572.

Mackintosh, J. Relay Interpretation: An Exploratory Study. 1983. University of London, Thesis.

Marrone, S. "Quality: A Shared Objective". The Interpreters' Newsletter, 5, 1993, pp. 35-41.

Marzocchi, C. “The Case for an Institution-Specific Component in Interpreting Research”. The Interpreters' Newsletter, 8, 1998, pp. 51-74.

Mason, I., ed. The Translator, v. 5, n. 2, special issue "Dialogue Interpreting", Manchester, St. Jerome Publishing, 1999.

Mesa, A.-M. L'interprète culturel : un professionnel apprécié. Étude sur les services d'interprétation : le point de vue des clients, des intervenants et des interprètes, Montréal, Régie régionale de la santé et des services sociaux de Montréal-Centre, 1997.

Morris, R. "The Moral Dilemmas of Court Interpreting”. The Translator, v. 1, n. 1, 1995, pp. 25-46.

Moser-Mercer, B. Quality in interpreting: Some methodological issues. The Interpreters' Newsletter, 7, 1996, pp. 43-55.

Cad. Trad., Florianópolis, v. 41, $\mathbf{n}^{0}$ esp. 2, p. 354-384, ago/dez, 2021. 382 
Niska, H. (coord). Quality Issues in Remote Interpreting. Anovar/Anosar estudios de traducción e interpretación. Editado por A. Álvarez Lugrís e A. Fernández Ocampo, Vigo, Universidade de Vigo, vol. I, 1999, pp. 109-121.

Pöchhacker, F. Simultandolmetschen als komplexes Handeln. Tübingen, Gunter Narr, 1994.

Pöchhacker, F. “The Community Interpreter's Task: Self-Perception and Provider Views". The Critical Link 2: Interpreters in the Community. Editado por: R. P. Roberts, S. E. Carr, D. Abraham e A. Dufour, Amsterdam and Philadelphia, John Benjamins, 2000.

Rehbein, J. "Ein ungleiches Paar - Verfahren des Sprachmittelns in der medizinischen Beratung". Interkulturelle Kommunikation, Editado por: J. Rehbein, Tübingen, Gunter Narr, 1985, pp. 420-448.

Robson, C. Real World Research. Oxford, Blackwell, 1993.

Roy, C. “A Sociolinguistic Analysis of the Interpreter's Role in Simultaneous Talk in Interpreted Interaction”. Multilingua, v. 12, n. 4, 1993, pp. 341-363.

Shlesinger, M. "Intonation in the Production and Perception of Simultaneous Interpretation". Bridging the Gap: Empirical Research in Simultaneous Interpretation. Editado por: S. Lambert e B. Moser-Mercer, Amsterdam and Philadelphia, John Benjamins, 1994, pp. 225-236.

Shlesinger, M. "Quality in Simultaneous Interpreting". Conference Interpreting: Currents Trends in Research. Editado por: Y. Gambier, D. Gile e C. Taylor, Amsterdam e Philadelphia, John Benjamins, 1997, pp. 123-131.

Strong, M. and S. Fritsch-Rudser. "The Subjective Assessment of Sign Language Interpreters," Sign Language Interpreters and Interpreting. Editado por: D. Cokely, Burtonsville (MD), Linstok Press, 1992, pp. 1-14.

Tommola, J. e J. "Lindholm. Experimental Research on Interpreting: Which Dependent Variable?". Topics in Interpreting Research. Editado por: J. Tommola, 1995, pp. 121-133, Turku, University of Turku Centre for Translation and Interpreting.

Cad. Trad., Florianópolis, v. 41, $\mathbf{n}^{0}$ esp. 2, p. 354-384, ago/dez, 2021.383 
Viezzi, M. Aspetti della Qualità in Interpretazione, Trieste, SSLMIT, 1996.

Vuorikoski, A.-R. "Simultaneous Interpretation - User Experience and Expectation". The Vital Link. Proceedings of the XIIIth World Congress of FIT. Editado por: C. Picken. London, Institute of Translation and Interpreting, v. 1, 1993, p. 317-327.

Wadensjö, C. Interpreting as Interaction. London and New York, Longman, 1998.

Yagi, Sane M. "Computational Discourse Analysis for Interpretation". Meta, v. 44, n. 2, 1999, pp. 268-279.

Franz Pöchhacker. E-mail: franz.poechhacker@univie.ac.at. https://orcid. org/0000-0002-8618-4060

Diego Maurício Barbosa. E-mail: diego.barbosa@ufg.br. https://orcid.org/00000003-1301-640X.

Paulo Roberto Mathias Manes. E-mail: paulomanesufg@gmail.com. https://orcid.org/0000-0002-6415-1364.

Patrícia Rodrigues Costa. E-mail: prcosta1986@gmail.com. https://orcid. org/0000-0002-3254-8914

Markus Johannes Weininger. E-mail: markus@cce.ufsc.br. https://orcid. org/0000-0002-0224-4557

Cad. Trad., Florianópolis, v. 41, n $^{0}$ esp. 2, p. 354-384, ago/dez, 2021. 384 